\title{
Evaluation of Scrotal Temperature in Different Testicular Shapes by Infrared Thermography in Braford Bulls*
}

\author{
Patrícia da Cruz Favaro', Gabriel Ribas Pereira², Flávio Antônio Barca Jr. ${ }^{1}$, \\ Marcelo Marcondes Seneda ${ }^{3}$, Augusto César Alves Assunção', Ivis Dias da Silva', \\ Elis Maria Victalina Franco', Victor Hugo Gonçalves Galdioli' \& Celso Koetz Jr.'
}

\begin{abstract}
Background: The mechanisms of testicular thermoregulation may influence the blood flow provided by the testicular artery, where the proper blood supply to the testicle is crucial for promotingspermatogenesis and reproductive function in bulls. The size and shape of the testicles are determined by genetic mechanisms and environmental effects. A better understanding of the relationships between the anatomical characteristics of the testicles and scrotum can support a better reproductive assessment. The purpose of the current study was to evaluate the testicular temperature of different scrotal shapes using infrared thermography in bulls.

Materials, Methods \& Results: We evaluated 132 Braford bulls with an average age of 24 months. The evaluation of breeding bull semen was performed prior to the beginning of the experiment. Then, animals were selected on the basis of the size of their testes, which was determined by dividing the average width by the average length. The scrotal circumference was measured with a millimeter tape positioned around the largest circumference. Testicular and ocular temperature measurements and analysis were conducted using an infrared thermal camera, Flir T440 with emissivity of 0.98 and thermal sensitivity of $0.05^{\circ} \mathrm{C}$. Testicular scrotum temperature and testicular shape were analyzed with one-way ANOVA using Minitab 16, and values of $P<0.05$ were considered statistically significant. We observed that $67.42 \%$ of testicle shapes were long-oval, and $32.58 \%$ were long-moderate. The testicular temperature was higher in bulls with the long-moderate shape compared to those with the long-oval shape $(P<0.05)$. The mean length was higher in long-moderate shaped testicles compared to those of the long-oval shape $(P<0.01)$. There was no significant differences in rectal and ocular temperatures or in scrotal circumference between bulls with long-moderate and long-oval shapes $(P>0.05)$. In addition, the mean width was lower in testicles of long-moderate shape compared to those of the long-oval scrotal format $(P<0.01)$.

Discussion: The results obtained showed that Braford bulls with the long-moderate testicular shape have a higher testicular temperature to maintain proper thermoregulation. The present study demonstrated that IRT can be used to evaluate the testicular temperature in animals with different scrotal conformations. In this study, Braford bulls showed lower length and width values for animals having long-moderate (9.21 and 5.22, respectively) and long-oval formats (8.56 and 5.56, respectively). In contrast, previous reports examining Nellore bulls between the ages of 17-20 months found a predominance of the long oval shape followed by the long-moderate shape, which indicates a change in testicular shape as age progresses, resulting in a rounder testicular shape. Perhaps other factors, such as the external cremaster muscle and tunica dartos, cause the testicles to be retracted towards the body at lower temperatures while at high temperatures, relaxation occurs. The prevailing testicular shape in Braford animals with a mean age of 24 months was the long-moderate shape. Thus, testicles with a larger surface area will have lower temperatures because they can dissipate heat more easily than testicles with lower surface area. The results suggest that the long-moderate scrotum format may influence the testicular temperature in mature Braford bulls.
\end{abstract}

Keywords: testicular thermoregulation, testicular shape, infrared thermography, Braford bulls.

DOI: $10.22456 / 1679-9216.96113$

Received: 8 July 2019

Accepted: 22 0ctober 2019

Published: 27 November

2019

*Article based on a Thesis submitted by the senior author in partial fulfillment of requirements for the Master of Science Degree. ${ }^{1}$ Animal Production Laboratory, Animal College of Veterinary Medicine \& ${ }^{2}$ Post-Graduated Program in Health and Animal Production, School of Veterinary Medicine, University of Northern Paraná (UNOPAR), Arapongas, PR, Brazil. ${ }^{3}$ REPROA - Animal Reproduction Laboratory, Department of Animal Science, State University of Londrina (UEL), Londrina, PR. CORRESPONDENCE: C.Koetz Jr. [celsokoetzjr@yahoo.com.br]. Department of Animal Production UNOPAR. PR 218 Km 1. CEP 86702-705 Arapongas, PR, Brazil. 
P.C. Favaro, G.R. Pereira, F.A. Barca Jr., et al. 2019. Evaluation of Scrotal Temperature in Different Testicular Shapes by

\section{INTRODUCTION}

Animals subjected to locations with high external environmental temperatures may suffer testicular heat exchange and consequently have a lower reproductive efficiency. High testicular temperatures have been shown to decrease semen quality in bulls $[3,24]$. The production of viable spermatozoa depends on testicular physiological mechanisms, especially thermoregulation, since the temperature of the scrotum should be maintained 2 to $6^{\circ} \mathrm{C}$ below the body temperature $[11,13]$. Any change in scrotal temperature may impact physical conditions and result in economic losses to livestock production in subtropical and tropical regions of the world $[1,14]$. The use of non-invasive methods, such as infrared thermography (IRT), is considered an effective tool in the characterization of the scrotal surface temperature in bulls [11-13,16].

Bulls have testes with ovoid and symmetrical shapes that are wider than the spermatic funiculus [19]. However, some animals have testicles that are longer and thinner or narrower, resulting in a scrotal perimeter that is smaller than the average of the breed, although bull breeding soundness evaluation observes sperm quality and production similar to animals with spherical testicular shapes [18].

Different breeds showed variations in testicular shape, such as Brahman animals that have longer testicles, with a length and width greater than Hereford. Indeed, Bos taurus animals have an oval or globose testes format, and Bos indicus testicles are considered elongated [21]. Therefore, the purpose of the current study was to investigate if there is a relation between the testicular format and scrotal temperature using IRT.

\section{MATERIALS AND METHODS}

\section{Animals and study location}

We used 132 Braford bulls (3/8 Nellore - 5/8 Hereford) that had a mean age of 24 months at the beginning of the study. Animals were kept in the same environment and fed in a pasture of Brachiaria brizantha with mineral supplementation and water ad libitum during the entire experimental period. Temperature and humidity data were collected hourly by an automatic weather station at the National Institute of Meteorology (INMET) [9]. Calculation of the temperature-humidity index (THI) was used to estimate the microclimatic factors using the following equation described by Buffington et al. (1981) [6]: THI
$=\mathrm{Tdb}+0.36 \mathrm{X} \mathrm{Tdp}+41.5$, in which $\mathrm{Tdb}=$ dry-bulb air temperature $\left({ }^{\circ} \mathrm{C}\right)$ and $\mathrm{Tdp}=$ dew-point temperature $\left({ }^{\circ} \mathrm{C}\right)$. The experiment was conducted in Brazil, at the Boa Sorte Farm located at $51^{\circ} 14^{\prime} 10^{\prime \prime} \mathrm{W}$ longitude, 2330'10'S latitude, and $566 \mathrm{~m}$ altitude, with the climate classified as $\mathrm{Cfa}$, according to Köppen-Geiger. All procedures with animals in this study were approved by the Animal Ethical Committee (UNOPAR, approval number: P010/14).

\section{Reproductive evaluation}

The examination consisted of a comprehensive general clinical examination and special clinical examination at the beginning of the reproductive season, in August 2014. Animals were restrained in the standing position in a crush without sedation or tranquilization. Testicular format was obtaining by determining the ratio of the median testicular width (widths of left and right testis) and median testicular length (average lengths of the left and right testicle). Then, testicular shape was classified as spherical (ratio $>0.87$ ), oval-spherical ( 0.87 to 0.75$)$, long-oval ( 0.75 to $0.62)$, long-moderate ( 0.62 to 0.51$)$, and long $(<0.51)$, according to Bailey et al. [2]. Length and width measurements were performed using a caliper ruler. Then, the scrotal circumference (SC) was measured, and the testes were pulled down to the bottom of the scrotum, at which point a millimeter tape was positioned around the largest circumference. An immediate repetition of this operation was performed to confirm the results.

\section{Infrared thermography evaluation}

For measurement of testicular and ocular temperatures, we used a thermal camera FLIR T440 ${ }^{1}$ with emissivity of 0.98 and thermal sensitivity of $0.05^{\circ} \mathrm{C}$. All IRT evaluations were performed between 14:00 and 18:00. The mean temperature of the scrotal surface was evaluated by positioning the infrared camera $1.5 \mathrm{~m}$ from each testicular pair oriented perpendicular to the scrotum. Two linear lines (Li1 and Li2) were used to select the left and right testicle distance to measure the mean testicular temperature (Figure 1A, B). In addition, a lateral image 1 $\mathrm{m}$ from each animal's head was recorded, and a circle was drawn around the orbital region, including the ocular globe, the skin surrounding the ocular cavity, and the lacrimal gland, to evaluate the animal's thermal status [7]. The IRT measurement and analysis were conducted according to Westermann et al. [23]. Thermograms images were later analyzed by FLIR Tools ${ }^{1}$ for iPads ${ }^{2}$. Then, animal rectal temperature was obtained using a digital thermometer. 


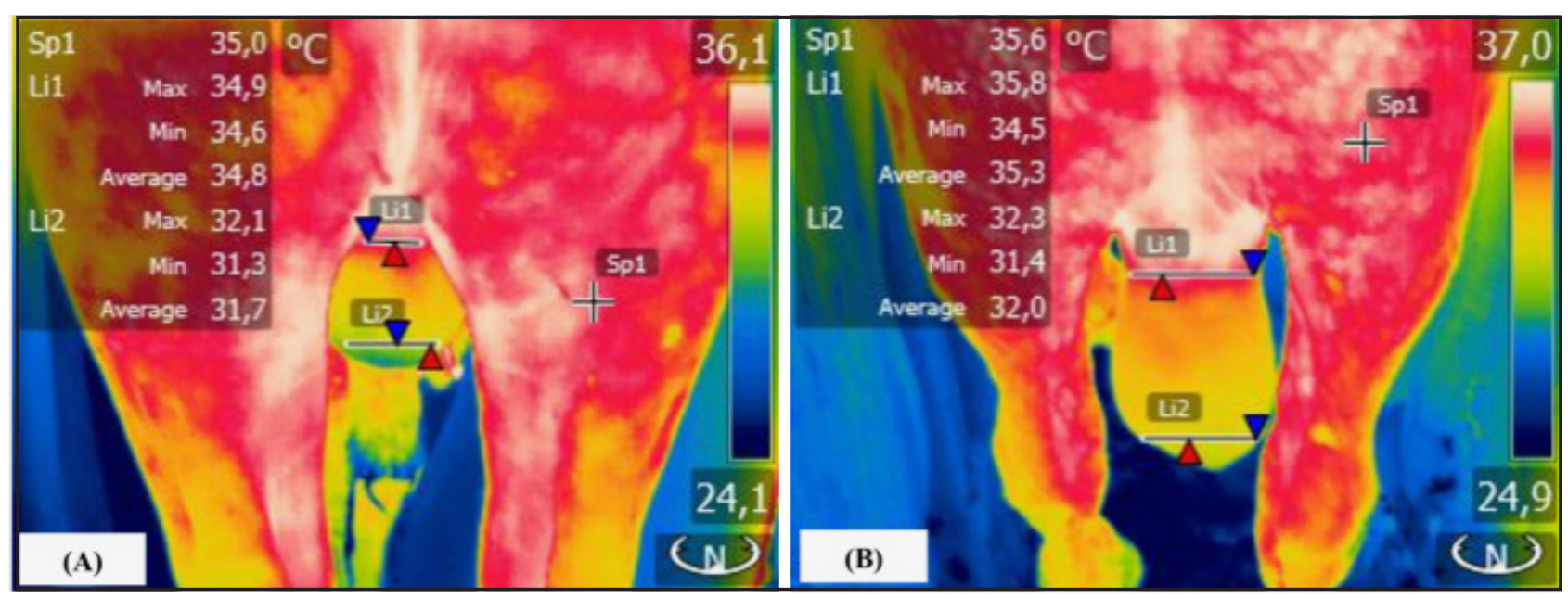

Figure 1. A- Infrared thermography images of the long-oval testicular scrotum in Braford bulls. B- Infrared thermography images of the long-moderate testicular scrotum in Braford bulls. Li1 (Line 1), Li2 (Line 2), Min (Minimum), Max (Maximum).

\section{Statistical analysis}

All variable parameters were tested for normality. Scrotal, rectal and ocular temperatures and testicular format were analyzed with a one-way ANOVA. Tukey's test was used as the mean test. All the calculations were performed using the statistical package Minitab $16^{3}$ (Version 10.0) with the minimum level of significance set at $5 \%$.

\section{RESULTS}

The average THI in the experimental period was 68 . The predominant testicular shape was the long-oval shape, occurring in $67.42 \%(89 / 132)$ of the tested bulls; $32.58 \%$ (43/132) of the bulls had a long-moderate shape. Testicular temperature was higher in bulls with the long-moderate shape $\left(34.3^{\circ} \mathrm{C}\right)$ compared to the long-oval shape $\left(33.8^{\circ} \mathrm{C}\right)(P<0.05$; Table 1). Mean length was higher in long-moderate testicles compared to those with the long-oval shape (9.21 vs $8.56 \mathrm{~cm} ; P<0.01)$. In addition, the mean width was lower in the long-moderate shape (5.22 $\mathrm{cm})$ compared to the long-oval shape $(5.59 \mathrm{~cm} ; P<$ 0.01). There was no significant differences in rectal and ocular temperatures or in scrotal circumference between bulls with long-moderate and long-oval shapes $(P>0.05)$.

Table 1. Rectal, ocular and testicular temperatures $\left({ }^{\circ} \mathrm{C}\right)$, scrotal circumference and biometric measurements of testicular shapes in Braford bulls.

\begin{tabular}{|c|c|c|c|c|c|c|c|c|c|}
\hline \multirow{2}{*}{ Variable } & \multicolumn{4}{|c|}{ Long-moderate } & \multicolumn{4}{|c|}{ Long-oval } & \multirow{2}{*}{$P$-value } \\
\hline & Mean \pm SD & Min & Max & $\mathrm{CV}$ & Mean \pm SD & Min & Max & $\mathrm{CV}$ & \\
\hline Rectal temp & $39.22 \pm 0.3^{\mathrm{A}}$ & 38.2 & 40.5 & 0.9 & $39.17 \pm 0.2^{\mathrm{A}}$ & 38.7 & 39.9 & 0.6 & 0.460 \\
\hline Ocular temp & $34.48 \pm 1.0^{\mathrm{A}}$ & 31.4 & 36.7 & 2.9 & $34.35 \pm 1.1^{\mathrm{A}}$ & 32.6 & 37.0 & 3.1 & 0.516 \\
\hline Testicular temp & $34.32 \pm 1.3^{\mathrm{A}}$ & 30.9 & 37.3 & 3.7 & $33.80 \pm 0.8^{\mathrm{B}}$ & 32.0 & 35.4 & 2.5 & $0.018^{*}$ \\
\hline $\mathrm{SC}(\mathrm{cm})$ & $29.89 \pm 3.6^{\mathrm{A}}$ & 22.0 & 40.0 & 12.2 & $30.60 \pm 2.8^{\mathrm{A}}$ & 24.0 & 36.0 & 9.1 & 0.259 \\
\hline Length $(\mathrm{cm})$ & $9.21 \pm 1.1^{\mathrm{A}}$ & 7.0 & 14.5 & 12.4 & $8.56 \pm 0.7^{\mathrm{B}}$ & 6.75 & 9.75 & 8.4 & $0.001^{*}$ \\
\hline Width $(\mathrm{cm})$ & $5.22 \pm 0.6^{\mathrm{A}}$ & 4.0 & 7.5 & 12.0 & $5.59 \pm 0.4^{\mathrm{B}}$ & 4.5 & 6.5 & 7.8 & $0.001^{*}$ \\
\hline
\end{tabular}

temp: temperature; SD: standard deviation; Min: minimum; Max: maximum; CV: coefficient variation; SC: scrotal circumference. ${ }^{*}$ Within a row, different capital letters differ statistically $(P<0.05)$.

\section{DISCUSSION}

The present study demonstrated that IRT can be used to evaluate the testicular temperature in animals with different scrotal conformations. In the current study, the obtained THIs were considered below the temperature that impairs physiological disequilibrium due to thermal stress in animals, and thus it is likely that neither temperature nor humidity was high enough to cause testicular damage that may lead to direct consequences on testicular shape [13]. Recently, Brangus 
breed bulls showed a mean testicular gradient of 4.2, indicating a higher temperature gradient compared to Nelore (2.1) and Braford (3.3; 3/8 Nelore x 5/8 Hereford) bulls evaluated at the Pantanal region of Brazil [17]. The Braford breed is a mix of Bos taurus and Bos taurus indicus (3/8 Nelore x 5/8 Hereford), showing a significant adaptation to tropical and subtropical regions and presenting higher genetic potential to improve productivity efficiency. These characteristics are very important for the continuing development of beef cattle production in Brazil and other wet and dry tropical regions. Our data suggested that Braford bulls having a long-moderate shape have a higher testicular temperature to maintain the proper thermoregulation.

In the current study, Braford bulls showed lower length and width values for those animals having long-moderate (9.21 and 5.22, respectively) and longoval formats (8.56 and 5.56, respectively). In contrast, Nellore bulls aged 17-20 months had a predominance of the long-oval shape followed by the long-moderate shape, which indicates a change in testicular shape as age progresses, resulting in a rounder testicular shape [22]. Thus, these shapes with a larger surface area will have lower temperatures because they can dissipate heat more easily unlike testicles with less surface area.

In addition, scrotal circumference was similar for shapes that were long-moderate (29.9) and longoval (30.6), demonstrating that Braford animals have a higher scrotal circumference than animals with testicles that are more oval at 22-24 months of age [20]. The size and shape of the testicles are determined by genetic mechanisms and environmental effects, such that Bos taurus indicus bulls that have longer testicles and thinner scrotal skin compared to Taurine bulls $[8,20]$. These two factors contribute to a better rate of heat exchange, with an increased exchange area and a thinner physical barrier [4,5]. When compared to bulls of different breeds, B. taurus indicus have an increased number of sweat glands in the skin of the scrotum of different sizes and shapes and a longer testicular artery relative to the size of the testicle, causing them to lose heat more easily through sweating [5]. This condition allows them to be more tolerant to high temperatures compared to B. taurus cattle [10]. These traits allow for better heat dissipation and require less blood.

With the expansion of Braford used in Brazil and South America, it is important to optimize breeding systems in tropical and subtropical climates developing new strategies to identify accurately the impact of changes in the reproductive performance of bulls. The prevailing testicular shape in Braford animals with a mean age of 24 months was the long-moderate shape. Indeed, testicular shape is important to facilitate the thermoregulation process, where more elongated or oval testicles show a different surface of interaction with the external environment and heat exchange.

\section{CONCLUSION}

The present study demonstrates that testicular scrotums with larger surface areas have lower temperatures because they can dissipate heat more easily. In addition, we inferred that IRT can be used as an indirect method to assess changes in temperature gradients in bulls. The results suggest that the long-moderate scrotum format may influence testicular temperature in mature Braford bulls.

\section{MANUFACTURERS \\ ${ }^{1}$ FLIR Systems Inc., Wilsonville, OR, USA. \\ ${ }^{2}$ Apple Inc. Cupertino, CA, USA. \\ ${ }^{3}$ Minitab. State College, PA, USA.}

Acknowledgements. This work was supported by CNPq (Brazilian Council for Research - Universal Project 456724/2014-1 and 430900/2016-3). The authors thank Leme Pecuária for providing the animals and technical assistance for this study.

Declaration of interest. The authors report no conflicts of interest. The authors alone are responsible for the content and writing of the paper.

\section{REFERENCES}

1 Ahmed A., Tiwari R.P., Mishra G.K., Jena B., Dar M.A. \& Bhat A.A. 2015. Effect of Environmental heat stress on reproduction performance of dairy cows - A review. International Journal of Livestock Research. 5(4): 10-18.

2 Bailey T.L., Monke D., Hudson R.S., Wolfe D.F., Carson R.L. \& Riddell M.G. 1996. Testicular shape and its relationship to sperm production in mature Holstein bulls. Theriogenology. 46(5): 881-887.

3 Barth A.D. \& Bowman P.A. 1994. The sequential appearance of sperm abnormalities after scrotal insulation or dexamethasone treatment in bulls. Canadian Veterinary Journal. 35(2):93-102. 
4 Brito L.F., Silva A.E., Barbosa R.T. \& Kastelic J.P. 2004. Testicular thermoregulation in Bos indicus, crossbred and Bos taurus bulls: relationship with scrotal, testicular vascular cone and testicular morphology, and effects on semen quality and sperm production. Theriogenology. 61(2-3): 511-528.

5 Brito L.F., Silva A.E., Barbosa R.T., Unanian M.M. \& Kastelic J.P. 2003. Effects of scrotal insulation on sperm production, semen quality, and testicular echotexture in Bos indicus and Bos indicus x Bos taurus bulls. Animal Reproduction Science. 79(1-2): 1-15.

6 Buffington D.E., Collazo-Arocho A., Canton G.H., Pitt D., Thatcher W.W. \& Collier R.J. 1981. Black GlobeHumidity Index (BGHI) as comfort equation for dairy cows. Transactions of the ASAE. 24(3): 711-714.

7 Church J.S., Hegadoren P.R., Paetkau M.J., Miller C.C., Regev-Shoshani G., Schaefer A.L. \& SchwartzkopfGenswein K.S. 2014. Influence of environmental factors on infrared eye temperature measurements in cattle. Research in Veterinary Science. 96(1): 220-226.

8 Dowling D.F. 2009. The significance of the thickness of cattle skin. Journal of Agricultural Science. 62: 307-311.

9 INMET - Instituto Nacional de Meteorologia. 2014. Normais Climatológicas. Available from: http://www.inmet. gov.br. Updated 2014 Aug 16; Cited 2015 Feb 10.

10 Jian W., Duangjinda M., Vajrabukka C. \& Katawatin S. 2014. Differences of skin morphology in Bos indicus, Bos taurus, and their crossbreds. International Journal of Biometeorology. 58: 1087-1094.

11 Kastelic J.P., Cook R.B., Coulter G.H. \& Saacke R.G. 1996. Insulating the scrotal neck affects semen quality and scrotal/testicular temperatures in the bull. Theriogenology. 45(5): 935-942.

12 Kastelic J.P., Cook R.B., Coulter G.H. \& Wallins T.E. 1996. Environmental factors affecting measurement of bovine scrotal surface temperature with infrared thermography. Animal Reproduction Science. 41(3-4): 153-159.

13 Kastelic J.P., Cook R.B. \& Coulter G.H. 1997. Contribution of the scrotum, testes, and testicular artery to scrotal/ testicular thermoregulation in bulls at two ambient temperatures. Animal Reproduction Science. 45(4): 255-261.

14 Lunstra D.D. \& Coulter G.H. 1997. Relationship between scrotal infrared temperature patterns and natural-mating fertility in beef bulls. Journal of Animal Science. 75(3): 767-774.

15 Mader T.L., Johnson L.J. \& Gaughant J.B. 2010. A comprehensive index for assessing environmental stress in animals. Journal of Animal Science. 88(6): 2153-2165.

16 Menegassi S.R.O., Pereira G.R., Dias E.A., Rocha M.K., Carvalho H.R., Koetz Jr. C., Oberst E.R. \& Barcellos J.O.J. 2018. Infrared thermography as a noninvasive method to assess scrotal insulation on sperm production in beef bulls. Andrologia. 50(3): e12904.

17 Menegassi S.R.O., Pereira G.R., Bremm C., Koetz Jr. C., Lopes F.G., Fiorentini E.C., McManus C., Dias E.A., Rocha M.K., Lopes R.B. \& Barcellos J.O.J. 2016. Effects of ambient air temperature, humidity, and wind speed on seminal traits in Braford and Nellore bulls at the Brazilian Pantanal. International Journal of Biometeorology. 60(11): 1787-1794.

18 Monke D. 1987. Examination of the bovine scrotum, testicles, and epididymides. Part I. Compendium on Continuing Education for the Practicing Veterinarian. 9: 252-258.

19 Ott R.S. 1986. Breeding soundness examination of bulls. In: Morrow D.A. (Ed). Current Therapy in Theriogenology. Philadelphia: WB Saunders, pp.125-136.

20 Siqueira J.B., Oba E., Pinho R.O., Guimarães S.E.F., Miranda-Neto T. \& Guimarães J.D. 2012. Testicular shape and andrological aspects of young Nellore bulls under extensive farming. Revista Brasileira de Zootecnia. 41(3): 612-617.

21 Vale-Filho V.R., Pinheiro L.E.L. \& Nasrur P.K. 1986. Reproduction in zebu cattle. In: Morrow D.A. (Ed). Current Therapy in Theriogenology. Philadelphia: WB Saunders, pp.437-522.

22 Viu M.A.O., Magnabosco C.U., Oliveira Filho B.D., Lopes D.T., Porto R.N.G., Ferraz H.T. \& Gambarini M.L. 2015. Testicular biometry, semen quality and sexual maturity of Nellore young bulls raised in the Brazilian tropical savannah. Journal of Animal and Veterinary Advances. 14(6): 144-150.

23 Westermann S., Buchner H.H.F., Schramel J.P., Tichy A. \& Stanek C. 2013. Effects of infrared camera angle and distance on measurement and reproducibility of thermographically determined temperatures of the distolateral aspects of the forelimbs in horses. Journal of the American Veterinary Medical Association. 242(3): 388-395.

24 Wildeus S. \& Entwistle K.W. 1983. Spermiogram and sperm reserves in hybrid Bos indicus x Bos taurus bulls after scrotal insulation. Journal of Reproduction and Fertility. 69: 711-716. 